\author{
F. Médail, A. Baumel, M. Bou Dagher Kharrat, K. Diadema, M. Juin, N. \\ Legalliot, S. La Malfa, F. Mirleau, G. Nieto Feliner, L. Ouahmane, S. \\ Pironon, J.-P. Suc, J. Viruel \& H. Sanguin
}

\title{
The Carob tree: biogeography, ecology and cultural history of a neglec- ted Mediterranean tree
}

\author{
Médail, F., Baumel, A., Bou Dagher Kharrat, M., Diadema, K., Juin, M., Legalliot, N., La \\ Malfa, S., Mirleau, F., Nieto Feliner, G., Ouahmane, L., Pironon, S., Suc, J.-P., Viruel, J., \& \\ Sanguin, H.: The Carob tree: biogeography, ecology and cultural history of a neglected \\ Mediterranean tree. — Bocc. 28: 285-286. 2019. — ISSN: 1120-4060 printed, 2280-3882 \\ Key words: Ceratonia siliqua, Fabaceae, plant domestication.
}

The Mediterranean thermophilous woodlands were very early impacted by human activities, and are still highly threatened by the destruction and the alteration of their habitats. For forage and fruit trees, the recurring exchanges between natural populations and cultivated agroecosystems constituted a pivotal aspect in the process of Mediterranean fruit tree domestication. Nowadays determining the native status of Mediterranean fruit tree populations represents a major but difficult task for phylogeography because early human influences began just after post glacial migrations. Here we applied geographical genetic methods to tackle this issue for a neglected thermophilous tree, the Carob tree (Ceratonia siliqua L., Fabaceae) aiming at providing the first genetic diversity report across its entire distribution range. Carob tree is widely exploited for food and forage since Antiquity and currently for industrial, agricultural and soil restoration purposes. The origin of carob tree populations throughout the Mediterranean basin is supposed to be dependent of an historical process of dissemination by humans since its domestication in the Middle-East around 6,000-4,000 BC. However, previous palaeobotanical and vegetation studies stated that the carob is a widespread component of thermophilous forest vegetation and opened a debate about the native or feral status of its populations. The patterns of genetic diversity were compared for populations growing in natural, semi-natural or cultivated habitats. We examined the relative contribution to genetic differentiation of geographical distance, current and past environments and the role of human dissemination routes. Genetic diversity and differentiation analyses revealed unexpected geographical patterns calling for a new appraisal of the domestication pattern of the carob tree in the Mediterranean basin. This research was 
investigated in the framework of the DYNAMIC (Deciphering sYmbiotic Networks in cArob-based MedIterranean agro-eCosystems) French ANR-project.

Addresses of the authors:

Frédéric Médail ${ }^{1}$, Alex Baumel ${ }^{1}$, Magda Bou Dagher Kharrat ${ }^{2}$, Katia Diadema ${ }^{3}$, Marianick Juin ${ }^{1}$, Nicolas Legalliot ${ }^{1}$, Stefano La Malfa ${ }^{4}$, Fatma Mirleau ${ }^{1}$, Gonzalo Nieto Feliner ${ }^{5}$, Lahcen Ouahmane ${ }^{6}$, Samuel Pironon ${ }^{7}$, Jean-Pierre Suc ${ }^{8}$, Juan Viruel ${ }^{7}$ \& Hervé Sanguin ${ }^{9}, 10$,

${ }^{1}$ Aix Marseille Université, Institut Méditerranéen de Biodiversité et d'Ecologie marine et continentale (IMBE), UMR CNRS, IRD, UAPV, Technopôle de l'Environnement Arbois-Méditerranée, BP 80, 13545 Aix-en-Provence cedex 04, France. E-mail: frederic.medail@imbe.fr

${ }^{2}$ Université Saint-Joseph, Faculté des sciences, Laboratoire Caractérisation Génomique des Plantes, B.P. 11-514 Riad El Solh, Beyrouth 1107 2050, Lebanon.

${ }^{3}$ Conservatoire Botanique National Méditerranéen (CBNMed), 34 avenue Gambetta, 83400 Hyères, France.

${ }^{4}$ Department of Agricolture, Food and Environment (Di3A), University of Catania, Via Valdisavoia 5 - 95123 Catania, Italy.

${ }^{5}$ Real Jardín Botánico (CSIC), Plaza de Murillo 2, 28014 Madrid, Spain.

${ }^{6}$ Université Cadi Ayyad Marrakech, Faculté des Sciences Semlalia, Laboratoire d'Ecologie et Environnement, Morocco.

${ }^{7}$ Royal Botanic Gardens, Kew, Richmond, Surrey, TW9 3DS, United Kingdom.

${ }^{8}$ Institut des Sciences de la Terre Paris (ISTEP), UMR 7193, Laboratoire Evolution et Modélisation des Bassins Sédimentaires, Université P. et M. Curie - Paris 6, 75005 Paris, France.

${ }^{9}$ LSTM, Univ Montpellier, CIRAD, IRD, INRA, Montpellier SupAgro, Montpellier, France.

${ }^{10}$ CIRAD, UMR LSTM, F-34398 Montpellier, France. 